\title{
Diabetes mellitus as a risk factor for acute myocardial infarction in Asians and Europeans
}

\author{
K L WOODS, A SAMANTA, * A C BURDEN $\dagger$ \\ From the ${ }^{\star}$ Coronary Care Unit, Leicester Royal Infirmary, Department of Pharmacology and Therapeutics, \\ University of Leicester, and †Leicester General Hospital
}

SUMMARY Ischaemic heart disease is commoner among immigrants from the Indian subcontinent than among Europeans in the United Kingdom. The excess cannot be accounted for by differences in smoking, blood pressure, or lipid concentrations. There is, however, an increased prevalence of diabetes mellitus in the Asian population. Separate estimates of the relative risk of acute myocardial infarction associated with diabetes from parallel case-control studies were made to compare the importance of diabetes as a risk factor in the two ethnic groups. For Asians the relative risk was 3.3 (95\% confidence interval 1.9 to 5.8) and for Europeans 1.3 (1.0 to 1.7). Calculations of population attributable risk indicated that clinical diabetes mellitus accounts for $21 \%$ of the incidence of myocardial infarction in Asians but only 3\% of the incidence in Europeans.

Diabetes mellitus is of sufficient quantitative importance as a risk factor to account for the whole of the observed excess of deaths from ischaemic heart disease among Asians in the United Kingdom.

Ischaemic heart disease is commoner among immigrants from the Indian subcontinent (Asians) to the United Kingdom than among Europeans. ${ }^{1-3}$ From 1970 to 1978 the standardised mortality ratio for ischaemic heart disease in Asians in England and Wales was 119 for men and 128 for women. ${ }^{1}$ Studies in Leicestershire and east London have confirmed the increased risk of acute myocardial infarction among Asians. ${ }^{45}$ The incidence of ischaemic heart disease was also reported to be disproportionately high among Asian migrants in Trinidad and elsewhere. ${ }^{6}$

The increased risk of ischaemic heart disease among Asians cannot be attributed to a higher prevalence of the major known risk factors, namely smoking, hypertension, and hypercholesterolaemia. Smoking is probably not commoner among Asians than Europeans, ${ }^{7}$ with the exception of Bangladeshis. $^{72}$ This view is corroborated by the low mortality from carcinoma of the bronchus in Asians. ${ }^{2}$ Neither blood pressure ${ }^{8}$ nor dietary and plasma lipids ${ }^{7}$ seem to be higher in Asians than in Europeans.

Requests for reprints to Dr K L Woods, Department of Pharmacology and Therapeutics, Clinical Sciences Building, PO Box 65, Leicester Royal Infirmary, Leicester LE2 7LX.

Accepted for publication 16 March 1989
There is, however, clear evidence from national mortality statistics, ${ }^{2}$ from hospital activity analysis data, ${ }^{4}$ and from surveys ${ }^{90}$ of a higher prevalence of diabetes mellitus among Asians. The excess is of non-insulin dependent diabetes. It is generally accepted that clinical diabetes is a risk factor for ischaemic heart disease in the predominantly white populations in which the association has been measured, ${ }^{11-14}$ though lesser degrees of glucose intolerance are probably not. ${ }^{15} \mathrm{We}$ wished to establish whether clinical diabetes is of sufficient importance as a risk factor to account for the higher incidence of myocardial infarction among Asians. To this end we performed parallel case-control analyses in these two ethnic groups in Leicester, calculating for each the relative risk of myocardial infarction in diabetic individuals compared with non-diabetic individuals. These relative risk estimates were then used to calculate the proportion of the incidence of myocardial infarction in the two groups that was attributable to clinical diabetes mellitus (population attributable risk or aetiological fraction).

\section{Patients and methods}

We studied all 50 Asian and 443 European patients with myocardial infarction aged $\geqslant 45$ admitted to the coronary care unit, Leicester Royal Infirmary, from 
January 1987 to February 1988 inclusive. The diagnosis of myocardial infarction was based on the presence of at least two of the following criteria: a history suggestive of chest pain of cardiac type; evolving electrocardiogram changes with ST elevation; an increase in serum creatine kinase to at least twice the upper limit of the normal laboratory range. A standard patient record was completed by the admitting doctor as part of the admission procedure. It included the ascertainment of previously diagnosed diabetes mellitus and its treatment from the patient (using interpreters if necessary). Of the 51 European diabetic patients, $22 \%$ were taking insulin and $51 \%$ oral hypoglycaemic agents. For the 15 Asians with diabetes the corresponding figures were $60 \%$ and $27 \%$ respectively. No biochemcial or other results acquired during the hospital stay were used to establish the diabetic state for the purpose of this study. The doctor completing the patient record and assigning the diagnosis of myocardial infarction was not aware of the hypothesis being tested. Patients of Asian descent were identified as such in the coronary care unit database by inspection of names'; no attempt was made to classify subjects by place of birth.

Reference data for the prevalence of clinical diabetes in the base population from which the cases arose were obtained from a survey carried out in part of the catchment area of the hospital within the city of Leicester. The survey included about $35 \%$ of the Asian and $10 \%$ of the European adult population of the city and has been described in detail elsewhere. ${ }^{9}$ Cases of clinical diabetes mellitus were ascertained from analysis of diabetic clinic records and specialist health visitor records. The diagnosis was made on a documented history of thirst and polyuria and a random venous plasma glucose of $\geqslant 11.1 \mathrm{mmol} / 1$ in accordance with the World Health Organisation definition. ${ }^{16}$ The health visitor service for diabetic patients is an important part of the community care in the city and is notified of newly diagnosed cases by hospital medical and nursing staff and general practitioners. The population denominator was extrapolated from the 1981 census data. About $90 \%$ of the Asians originated from the Gujerat region of India, having migrated via East Africa. ${ }^{17}$

The relative risk of myocardial infarction associated with diabetes was estimated for Asians and Europeans separately. Confidence intervals were calculated by Miettinen's test based method. ${ }^{18}$ Stratified analysis was then performed for the age ranges $45-64$ and $\geqslant 65$ years; we derived overall estimates of relative risk and $95 \%$ confidence intervals for each ethnic group using precision based weights. ${ }^{19}$

We calculated population attributable risk $\left(A R_{\mathrm{p}}\right)$ for each ethnic group using the relevant age adjusted estimate of relative risk $\left(R_{\mathrm{p}}\right)$ and observed prevalence $\left(\mathbf{P}_{\mathrm{p}}\right)$ of clinical diabetes in the survey sample by the following formula ${ }^{20}$ :

$$
A R_{p}=\frac{P_{p}\left(R R_{p}-1\right)}{P_{p}\left(R_{p}-1\right)+1} \times 100 \%
$$

Confidence intervals for the population attributable risk were calculated from the normal approximation ${ }^{21}$ of the distribution of $\ln \left(1-\mathrm{AR}_{\mathrm{p}}\right)$.

\section{Results}

The large prevalence study in the population in the catchment area gave precise estimates of the age specific prevalence of diabetes mellitus in the two ethnic groups (figure). The excess of diabetes among Asians is of the non-insulin dependent type. For the present study all diabetes was first considered in a single category. Table 1 shows the results of the case control analyses for Asians. There was a highly significant association between diabetes and myocardial infarction among Asians, with an age adjusted point estimate of relative risk of 3.3 ( $p<0.0005$ ). The strength of the association was similar in both age strata, indicating lack of interaction between age and diabetes as determinants of risk.

Table 2 shows the results for the European study group. The age adjusted relative risk estimate of 1.3 was of borderline statistical significance at the $5 \%$ level. Relative risk was constant across the age ranges, as in the Asian group.

Table 3 shows the analysis by treatment (dichotomised into insulin-treated and treated by oral hypoglycaemic agents or diet or both) for each ethnic group. Among the Asians there is a strikingly high relative risk for insulin treatment of 9.9 (p < 0.0005 ) compared with a non-significant relative risk estimate for treatment with oral hypoglycaemic agents or diet. This observation should be interpreted cautiously because of the small numbers in the analysis and more data are needed to confirm it.

Calculations of population attributable risk from the overall estimates of relative risk and the observed Table 1 Case-control analyses for Asians

\begin{tabular}{llcl}
\hline Asians & Cases & Controls & $\begin{array}{l}\text { Relative } \\
\text { risk }(95 \% \text { CI })\end{array}$ \\
\hline Unstratified analysis: & 35 & 6143 & \\
$\quad \begin{array}{l}\text { Non-diabetic } \\
\text { Diabetic }\end{array}$ & 15 & 806 & $3.3(1 \cdot 8-5 \cdot 9)$ \\
$\begin{array}{l}\text { Stratum 45-64 years: } \\
\quad \text { Non-diabetic } \\
\text { Diabetic }\end{array}$ & 24 & 4308 & \\
$\begin{array}{l}\text { Stratum 65+ years: } \\
\quad \text { Non-diabetic }\end{array}$ & 10 & 527 & $3.4(1 \cdot 7-6 \cdot 8)$ \\
Diabetic & 11 & 1835 & \\
\hline
\end{tabular}

Adjusted risk ratio over age strata (variance weighted) $3 \cdot 3(1 \cdot 9-5 \cdot 8)$. 


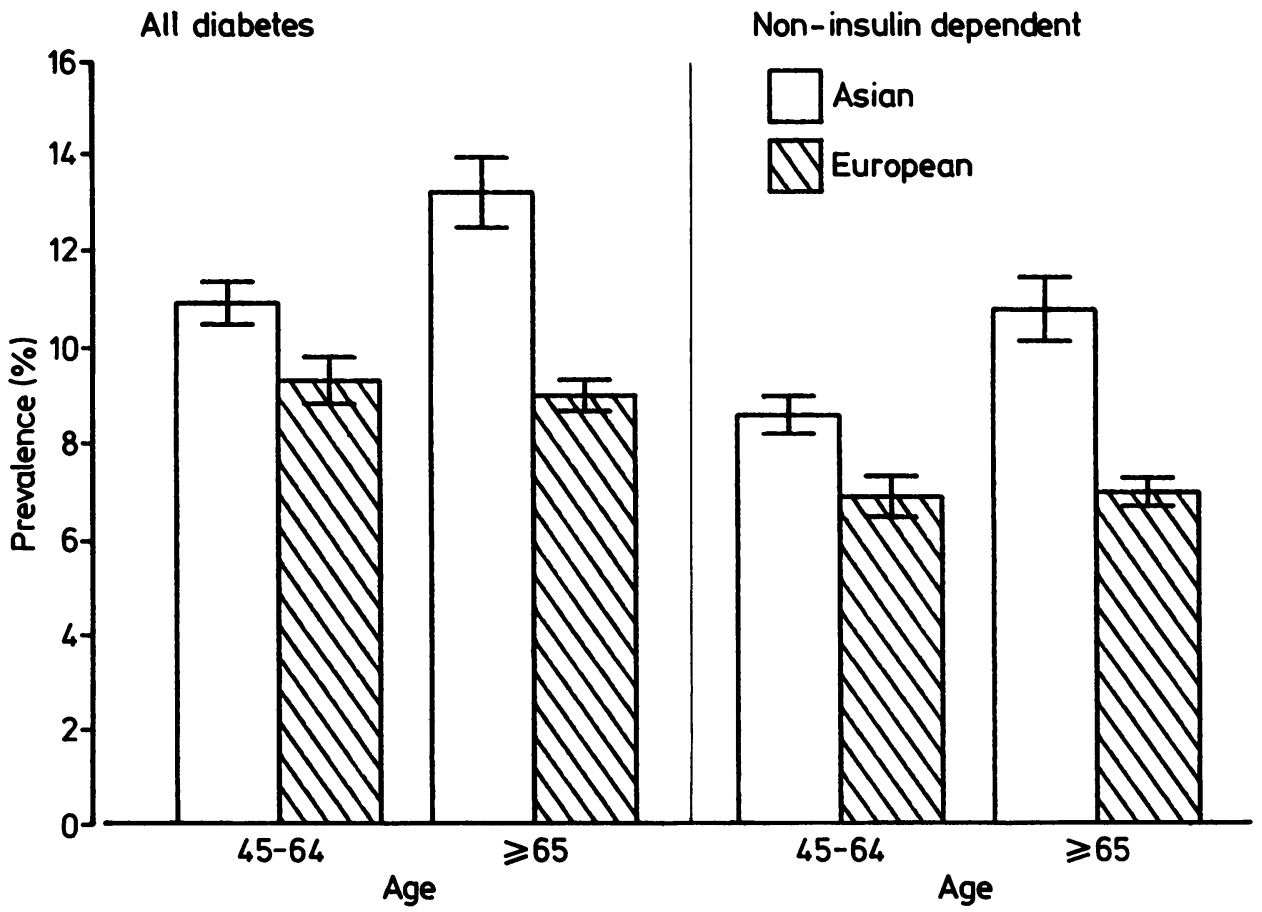

Figure Mean (SE) age-specific prevalence of known diabetes and of known non-insulin dependent diabetes in Asians and Europeans in Leicester.

prevalence of diabetes in the community indicate that $21 \%(95 \%$ confidence interval 5 to $34 \%$ ) of the incidence of acute myocardial infarction in Asians is attributable to clinical diabetes mellitus. For Europeans, the population attributable risk was 3\% ( 0 to $6 \%$ ). When we used the simplest model (in which standardised ischaemic heart disease mortality is equal in Asians and Europeans in the absence of the factor of diabetes and is then scaled up by 100/79 in Asians and 100/97 in Europeans to allow for the differential effect of this risk factor) the predicted

Table 2 Case-control analyses for European patients

\begin{tabular}{lrrl}
\hline Europeans & Cases & Controls & $\begin{array}{l}\text { Relative } \\
\text { risk }(95 \% \mathrm{CI})\end{array}$ \\
\hline $\begin{array}{l}\text { Unstratified analysis: } \\
\text { Non-diabetic }\end{array}$ & 392 & 9923 & \\
$\begin{array}{l}\text { Diabetic } \\
\text { Stratum 45-64 years: } \\
\quad \text { Non-diabetic }\end{array}$ & 51 & 993 & $1 \cdot 3(1 \cdot 0-1 \cdot 8)$ \\
$\quad \begin{aligned} \text { Diabetic } \\
\text { Stratum 65+ years: }\end{aligned}$ & 19 & 3189 & \\
$\quad$ Non-diabetic & 254 & 6734 & $1 \cdot 3(0 \cdot 8-2 \cdot 2)$ \\
Diabetic & 32 & 666 & $1 \cdot 3(0 \cdot 9-3 \cdot 3)$ \\
\hline
\end{tabular}

Adjusted risk ratio over age strata (variance weighted) 1.3(1.0-1/7). mortality from ischaemic heart disease in Asians was $123 \%$ of that in Europeans. This accords well with the observed standardised mortality ratios of 119 for Asian men and 128 for Asian women. ${ }^{1}$ This assumes that $(a)$ the combined effect of all coronary risk factors other than clinical diabetes is equal in the two ethnic groups, $(b)$ that there is a similar multiplicative interaction of diabetes with other risk factors in both groups, and $(c)$ that the case fatality rate is also equal. The validity of these assumptions is currently being tested in further studies.

Table 3 Analysis by treatment for both ethnic groups

\begin{tabular}{lrrl}
\hline & Cases & Controls & $\begin{array}{l}\text { Relative } \\
\text { risk }(95 \% \text { CI) }\end{array}$ \\
\hline Asian: & & & \\
$\quad$ Non-diabetic & 35 & 6143 & \\
Insulin & 9 & 160 & $9 \cdot 9(5 \cdot 4-18 \cdot 2)$ \\
$\quad$ Oral agents/diet & 6 & 646 & $1 \cdot 6(0 \cdot 7-3 \cdot 9)$ \\
European: & & & \\
$\quad$ Non-diabetic & 392 & 9923 & \\
Insulin & 11 & 236 & $1 \cdot 2(0 \cdot 7-2 \cdot 1)$ \\
Oral agents/diet & 40 & 757 & $1 \cdot 3(0 \cdot 9-1 \cdot 8)$ \\
\hline
\end{tabular}


Discussion

In the present study we made no estimate of relative risk of myocardial infarction in Asians and Europeans and its design does not permit such a calculation. The evidence that ischaemic heart disease is commoner among Asians than among Europeans in the United Kingdom is consistent from several sources, most notably national mortality statistics. Our objective was to measure the importance of diabetes mellitus as a coronary risk factor both for the individual (relative risk) and for the community (population attributable risk) within each ethnic group. The results show that clinical diabetes is more important by either criterion in Asians than in Europeans and is a risk factor of sufficient magnitude to account for the excess of deaths from ischaemic heart disease among Asians.

Many prospective studies of diabetes mellitus in relation to myocardial infarction have used some direct measure of glycaemia (with or without an oral glucose load) to establish the diabetic state. ${ }^{121422-24}$ Such an approach cannot validly be used in casecontrol studies because of the disturbance of metabolic control in the patients at the time of infarction. If tests are delayed until the recovery phase they can only be applied to survivors, who will be unrepresentative of all incident cases if early prognosis differs in patients with diabetes and those without, as has been reported. ${ }^{25}$ Case-control studies have distinct advantages of efficiency and statistical power over cohort studies and in order to use this study design we defined history of clinical diabetes as the factor of interest rather than any biochemical measure. This definition, which was also used in the Tecumseh cohort study, ${ }^{26}$ has the advantage of being categorical and obviates the need to divide continuous measures of glycaemia arbitrarily into ranges of normal, impaired glucose tolerance, and diabetic. In addition, a large body of prospective data has failed to provide convincing evidence that asymptomatic hyperglycaemia is a risk factor for ischaemic heart disease. ${ }^{15}$

Leicester Royal Infirmary provides coronary care facilities for the whole of the city and surrounding county without any differential referral patterns for patients with diabetes. The reference data came from a substantial sample of the base population providing the cases, rather than from "controls" chosen for the study. Selection bias was thereby avoided and statistical power maximised for the available number of cases. A potential disadvantage is the possibility of information bias since the diabetic state was not ascertained in exactly the same way in the cases and the controls. However, the methods were identical for both Asians and Europeans and any bias would be likely to operate equally in the two groups without invalidating the comparison between them. In addition, the finding of an increased relative risk in the Asians with diabetes is most striking in the insulin treated group, in whom diabetes is least likely to be incorrectly ascertained either for the cases or the controls.

It is unlikely that insulin treatment itself increases the risk of myocardial infarction among Asians with diabetes. Insulin dependent (type I) diabetes seems to be no more common among Asians than among Europeans, certainly during childhood. ${ }^{27}$ It is more plausible that insulin treatment among adult Asians identifies a group of individuals with type II diabetes who have failed to be controlled by diet and oral hypoglycaemic agents.

The mechanism of the association between diabetes mellitus and acute myocardial infarction is not yet clear. ${ }^{28} \mathrm{~A}$ recent study of coronary risk factors in east London found that Bangladeshis had a threefold greater prevalence of diabetes than Europeans. ${ }^{7^{a}}$ In addition, Bangladeshis without a history of diabetes showed a twofold greater serum insulin response to an oral glucose load than Europeans. In the light of these data a unifying hypothesis was proposed whereby relative insulin resistance among Asians leads to hyperinsulinaemia and consequent lipoprotein abnormalities favouring the development of coronary atherosclerosis. It is important to recognise, however, that acute myocardial infarction represents the summation of two processes: the gradual development of coronary atherosclerosis and a subsequent rapid occlusion which is nearly always thrombotic. ${ }^{29}$ The link between diabetes and myocardial infarction might operate through either or both of these to produce the association observed here.

Under certain circumstances the relative risk associated with a particular factor can be influenced by the prevalence and strength of other risk factors in the population studied. ${ }^{30}$ Further study of the known coronary risk factors in Asians is needed both to clarify the link between diabetes and myocardial infarction and to assist the planning of primary prevention. Mortality from ischaemic heart disease in the United Kingdom is now among the highest is the world and calls for an ambitious policy to control risk factors as has been successfully applied in Finland. ${ }^{31}$ The present study indicates that primary prevention among Asians should be particularly directed towards those with diabetes.

We thank Mrs Barbara Fent and Mrs Sue Fletcher for their help with data collection and Professor Michael Clarke for his comments. 


\section{References}

1 Marmot M, Adelstein A. Immigrant mortality in England and Wales 1970-1978. Population Trends 1983;33:14-7.

2 Balarajan R, Bulusu L, Adelstein AM, Shukla V. Patterns of mortality among migrants to England and Wales from the Indian subcontinent. $\mathrm{Br} \mathrm{Med} J$ 1984;289:1185-7.

3 Marmot MG, Adelstein AM, Bulusu L. Lessons from the study of immigrant mortality. Lancet 1984;i: 1455-7.

4 Donaldson LJ, Taylor JB. Patterns of Asian and nonAsian morbidity in hospitals. $\mathrm{Br}$ Med $J$ 1983;286: 949-51.

5 Tunstall Pedoe H, Clayton D, Morris JN, Brigden W, McDonald L. Coronary heart-attacks in east London. Lancet 1975;ii:833-8.

6 Beckles GLA, Miller GS, Kirkwood BR, Alexis SD, Carson DC, Byam NTA. High total and cardiovascular mortality in adults of Indian descent in Trinidad, unexplained by major coronary risk factors. Lancet 1986;i:1298-300.

7 McKeigue PM, Marmot M, Adelstein AM, et al. Diet and risk factors for coronary heart disease in Asians in northeast London. Lancet 1985;ii:1086-9.

7a McKeigue PM, Marmot MG, Syndercombe Court YD, et al. Diabetes, hyperinsulinaemia, and coronary risk factors in Bangladeshis in East London. Br Heart $J$ 1988;60:390-6.

8 Cruickshank JK, Jackson SHD, Beevers DG, et al. Similarity of blood pressure in blacks, whites and Asians in England. The Birmingham factory study. $J$ Hypertens 1985;3:365-71.

9 Samanta A, Burden AC, Fent B. Comparative prevalence of non-insulin-dependent diabetes mellitus in Asian and white Caucasian adults. Diabetes Research and Clinical Practice 1987;4:1-6.

10 Mather H, Keen H. The Southall Diabetes Survey: prevalence of known diabetes in Asians and Europeans. Br Med J 1985;291:1081-4.

11 Garcia MJ, McNamara PM, Gordon T, et al. Morbidity and mortality in diabetics in the Framingham population. Sixteen year follow-up study. Diabetes 1974;23:105-11.

12 Kannel WB. Lipids, diabetes and coronary heart disease: insights from the Framingham study. Am Heart $J$ 1985;110:1100-7.

13 Jarrett RJ, McCartney PM, Keen H. The Bedford survey: ten year mortality rates in newly diagnosed diabetics, borderline diabetics and normoglycaemic controls and risk indices for coronary heart disease in borderline diabetics. Diabetologia 1982;22:79-84.

14 Fuller JH, Shipley MJ, Rose G, et al. Mortality from coronary heart disease and stroke in relation to degree of glycaemia: the Whitehall study. $B r$ Med J 1983; 287:867-70.

15 International Collaborative Group. Joint discussion. $J$ Chronic Dis 1979;32:829-37.

16 World Health Organisation. Diabetes mellitus. WHO Tech Rep Ser 1985; No. 727.

17 Leicester City Council and Leicestershire County Council. Survey of Leicester 1983. 1983.

18 Miettinen OS. Estimability and estimation in casereferent studies. Am J Epidemiol 1976;103:226-35.

19 Kleinbaum DG, Kupper LL, Morgenstern H. Epidemiologic research. Belmont, California: Lifetime Learning Publications, 1982.

20 Cole $P$, MacMahon B. Attributable risk percent in casecontrol studies. Br J Prev Soc Med 1971;25:242-4.

21 Walter SD. The distribution of Levin's measure of attributable risk. Biometrika 1975;62:371-4.

22 Heyden S, Heiss G, Bartel AD, et al. Sex differences in coronary mortality among diabetics in Evans County, Georgia. J Chronic Dis 1980;33:265-73.

23 Barrett-Connor E, Wingard DL. Sex differential in ischaemic heart disease mortality in diabetics: a prospective population-based study. Am J Epidemiol 1983;118:489-96.

24 Pan W-H, Cedres LB, Liu K, et al. Relationship of clinical diabetes and asymptomatic hyperglycaemia to risk of coronary heart disease mortality in men and women. Am J Epidemiol 1986;123:504-16.

25 Smith JW, Marcus FI, Serokman R. Prognosis of patients with diabetes after acute myocardial infarction. Am J Cardiol 1984;54:718-21.

26 Butler WJ, Ostrander LD, Carman WJ, Lamphiear DE. Mortality from coronary heart disease in the Tecumseh study. Am J Epidemiol 1985;121:541-7.

27 Samanta A, Burden AC, Jones GR, et al. Prevalence of insulin dependent diabetes mellitus in Asian children. Diabetic Medicine 1987;4:65-7.

28 Salonen J. Non-insulin dependent diabetes and ischaemic heart disease. $\mathrm{Br} \mathrm{Med} \mathrm{J} \mathrm{1989;298:1050-1.}$

29 Fox KM, Shapiro LM. Heart disease in Asians in Britain. Br Med J 1988;297:311-2.

30 Rothman KJ. Causes. Am J Epidemiol 1976;104: 587-92.

31 Tuomilehto J, Geboers J, Salonen JT, et al. Decline in cardiovascular mortality in North Karelia and other parts of Finland. Br Med J 1986;293:1068-71. 